Revista de la red interuniversitaria de estudios sobre las literaturas rioplatenses contemporáneas en Francia

$18 \mid 2018$

El río y la ciudad

\title{
Fuera de campo
}

\section{Guillaume Contré}

\section{OpenEdition}

Journals

\section{Edición electrónica}

URL: http://journals.openedition.org/lirico/5743

DOI: $10.4000 /$ lirico. 5743

ISSN: 2262-8339

Editor

Réseau interuniversitaire d'étude des littératures contemporaines du Río de la Plata

Referencia electrónica

Guillaume Contré, «Fuera de campo », Cuadernos LIRICO [En línea], 18 | 2018, Puesto en línea el 14 octubre 2018, consultado el 01 mayo 2019. URL : http://journals.openedition.org/lirico/5743 ; DOI 10.4000/lirico.5743

Este documento fue generado automáticamente el 1 mayo 2019.

\section{(c) (i) (9)}

Cuadernos LIRICO está distribuido bajo una Licencia Creative Commons Atribución-NoComercialSinDerivar 4.0 Internacional. 


\section{Fuera de campo}

\section{Guillaume Contré}

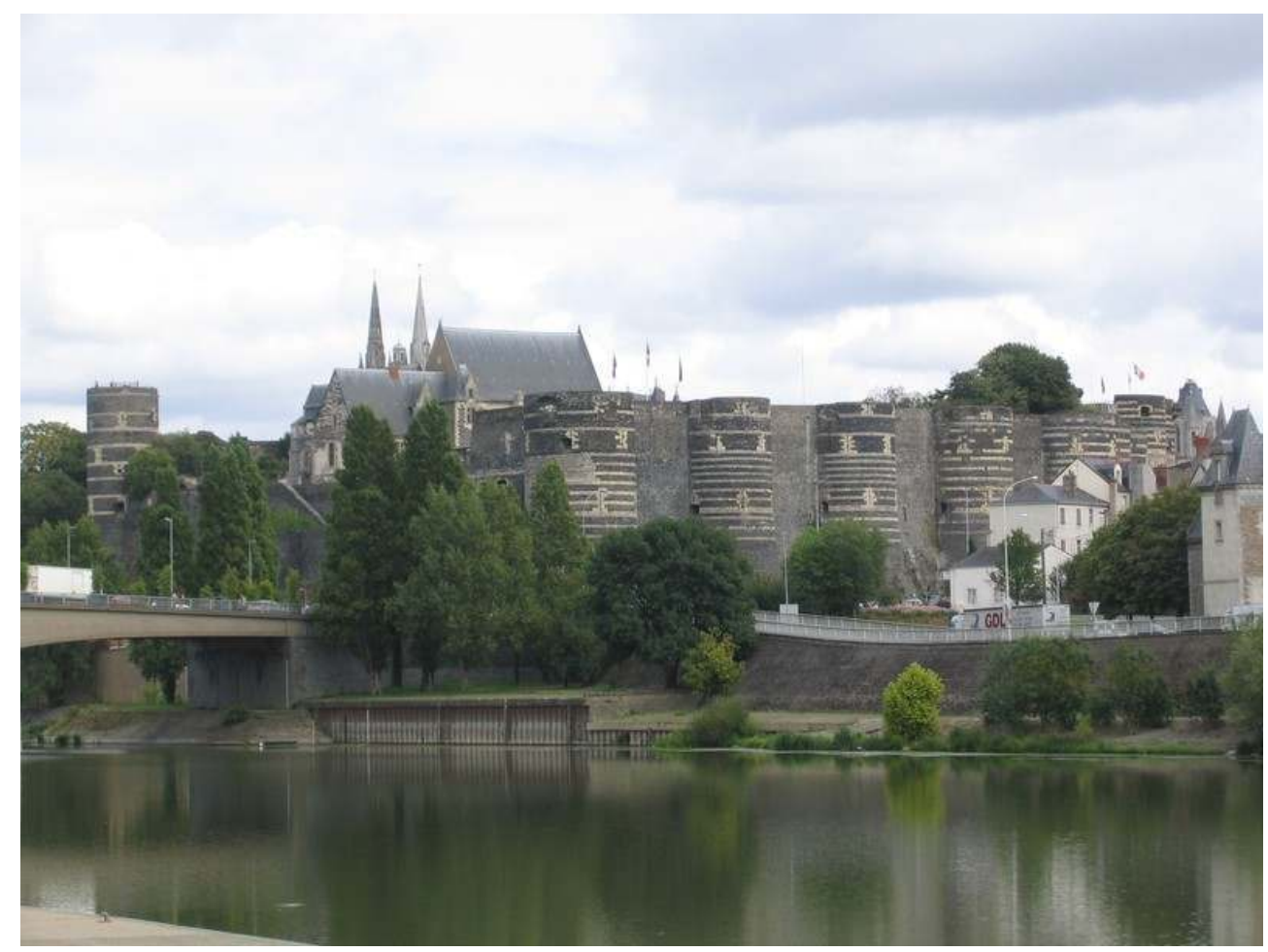

En esta foto sin gracia ni encanto especial, anónima (por supuesto que alguien se tomó el trabajo de sacarla y si acaso conociera el nombre del fotógrafo, dada la poca personalidad del resultado, me encontraría en la imposibilidad de citarlo), encontrada en Google, se ven dos de los principales atractivos de la ciudad donde nací, hace ya algunas décadas: en primer plano, el río Maine, una superficie lisa, vagamente verde, lo que se dice un espejo de agua (aunque ningún rostro y mucho menos el mío se ve reflejado ahí), y, dominándolo (cierto aspecto marcial, imponente, del edificio insta a usar esta palabra), el castillo del rey René, nombre comúnmente usado aunque, al parecer, de manera algo impropia, ya que existen por lo menos dos castillos atribuidos a este rey, el otro situado en la ciudad sureña de Tarascón. En rigor, se divisa apenas en la foto el tercer encanto turístico de la 
ciudad, el campanario de la catedral, muy antigua, ya que dentro del conjunto de piedras que la componen deben de sobrevivir algunas provenientes directamente de la época de su lejana fundación, en el siglo XI (o sea que la catedral le lleva dos siglos al castillo, edificado en los tiempos del rey Luis IX, también conocido como San Luis, hijo de Blanca de Castilla y primo hermano del rey español Fernando III, al parecer también apodado "el santo"; uno de los hijos de San Luis, Felipe, que le sucedió en el trono, fue apodado "el atrevido", como si la santidad se desgastara; pero santidad o no, eran tiempos de cruzadas). La catedral, entonces, pese a tantos reyes y tantas piedras y tantas remodelaciones y tantos años, no importa, dejémosla de lado. Además, no me siento muy a gusto en el rol de guía turístico (entre otras cosas porque los escasos y dudosos datos que voy soltando provienen de una apurada lectura de Wikipedia). Lo importante de esta foto no es tanto lo que se ve en ella (que después de todo no dista mucho de lo que podría verse en muchas otras ciudades francesas: un castillo medieval, una catedral de estilo románico pasado a gótico, un río más o menos verde), sino lo que yo puedo ver o elijo ver. Es decir que lo que importa de esta foto anónima y -para qué mentirse- bastante fea (este tipo de foto que se veían antes en los calendarios distribuidos cada año por los carteros a cambio de una pequeña propina; la alternativa era, si no, un calendario con fotos de gatitos o cachorros), lo que importa, decía, es como yo voy proyectándome mientras la estoy mirando. Lo que voy proyectando, obviamente, son recuerdos, aun cuando parece difícil proyectar recuerdo alguno ante una imagen así, tan neutra que lo que retrata parece falso, un decorado, o (lo que es lo mismo) una idea de paisaje perfecto, donde todo estaría en su lugar, donde no faltaría nada y donde no hubiera nada que agregar. Pero esto no es completamente cierto: esta imagen, que aspira a la neutra perfección enlatada de la foto turística o de autopromoción municipal, tiene algunos toques amateurs que delatan sus orígenes dudosos (Google, como quedo dicho; sacada de un "blog" o algo por el estilo llamado Tout Angers, tal el nombre de la pequeña ciudad del oeste de Francia donde nací). Algo no va en la foto, algo está de más, sobrando y perturbando sus pretensiones de equilibrio, de mundo perfecto en miniatura: este detalle es el camión que se ve a la derecha, en cuyo acoplado se pueden leer tres letras gigantes, una sigla misteriosa para mí (aunque no costaría mucho hacer una búsqueda para desvelar el misterio): GDL. Este vehículo (que no es el único en la foto, pero sí el único que molesta, o que a mí me molesta) no cuadra con el conjunto, probablemente por esta sigla que, dentro de un conjunto de anonimidad, de mundillo perfecto sin seres humanos, sin historia, sin pasado ni futuro, puro presente tedioso, con una luz bella y perfecta, perfectamente bella como siempre debería ser la luz, con un cielo despejado como siempre debe despejarse un obediente cielo en este tipo de fotos (¿quién tomaría una foto turística bajo la lluvia o con un cielo desesperadamente encapotado?), esta sigla, decía, que en un conjunto de supuesta perfección deshumanizada se vuelve, curiosamente, demasiado humana. Es decir que estas tres letras cualquieras (GDL, pero daría lo mismo si se trataría de OMV o PTL o cualquier otra combinación) esconden una historia, una economía, la idea de un traslado de mercancías (alguien está manejando este camión, y a este alguien le importa que lo que va llevando llegue, como se dice, a buen puerto). O sea que este camión feo con sus tres letritas feas nos cuenta la verdad: en este mundo idílicamente turístico, en este retrato congelado de lo imperecedero, hay gente, hormiguitas que tienen que afanarse para sobrevivir, en un fragor de actividades incesantes que viene a contradecir la paz del río -el espejo ese de agua- y la mudez altiva de estas viejísimas piedras, las del imponente castillo medieval, las de la catedral situada más allá y que, como dije, no nos importa ahora. Pero la verdad es que tampoco el camión nos importa, ni el castillo; lo que importa, 
como iba diciendo más arriba, es lo que yo veo en la foto, pero no lo que yo veo que está en la foto (como este camión o el puente que cruza el río, o este cielo, del que, mirándolo ahora con más detenimiento, me doy cuenta de que no es tan despejado como creí verlo al principio), sino, digo, lo que voy proyectando desde una distancia tan geográfica como temporal que podría llamarse recuerdo o pasado o juventud. Es una fatalidad contra la que ni yo ni nadie puede luchar: cuando uno ve (aún sin quererlo, aún queriendo ver otra cosa) una foto del lugar donde nació y creció, pero donde ya no vive desde hace años, se pone a recordar. 0 por lo menos a tratar de hacerlo, como si no acordarse de nada fuera un pecado imperdonable, una traición o, peor: una falta de vida. Mirar una foto de lugares del pasado (no importa si en la actualidad estos lugares siguen existiendo, a veces intocados o casi, salvo por detalles intrascendentes) y no proyectar nada de sí mismo equivaldría a confesar lo inconfesable: no he vivido. Pero yo sí, pese a todo, he vivido. Quiero decir que he vivido en este lugar (no en las orillas del río, pero cerca, en el centro de la ciudad). Entonces, si miro la foto, algo debería pasar, alguna emoción estremecerme. ¿O no? Tengo también, después de todo, el derecho a la indiferencia. A la mente en blanco, a la mudez, al aburrimiento. Tengo todos estos derechos, sí, pero también el de sacar provecho de la experiencia, la de mirar una foto carente de interés de un lugar en el que ya no vivo y que suelo visitar ahora muy de vez en cuando, casi como un extraño (o por lo menos con una extrañada indiferencia, como si existiera una distancia infranqueable, o como si yo desearía la existencia de esta distancia, a lo mejor ficticia). Además, y es tiempo de confesarlo, no todos mis recuerdos (que los tengo, y muchos, y con esforzarme un poquito podría encontrar tantos más) de mi juventud y adolescencia en Angers son gratos. Algunos, sí, seguramente; otros, relacionados, muchos, al colegio, este pequeño infierno para los tímidos, decididamente, no. Yo era un chico retraído, con dificultades para comunicarme, y de esto resulta ahora una dificultad para manejar los recuerdos. Supongo que hay ahí una lógica, aunque no me interesa indagar para entender cuál. A lo mejor es demasiado obvia y no vale la pena. Muchas cosas no valen la pena, otras sí. El tema es saber cuáles, y nuestro criterio, a veces, no ayuda. Pero no importa. Puedo mirar el castillo del rey René (1409-1480; un rey conocido en castellano como "Renato I de Nápoles", parece que fue también rey de alguna provincia de Italia, en esta época remota de fronteras confusas y móviles y de matrimonios tácticos, supongo que uno podía ser rey en varios lugares a la vez, o en lugares sucesivos), puedo mirar este castillo, decía, y acordarme de cuánto me impresionaba de chico (me contaron que en un pasado inverificable había sido más alto aún), o recordar un dato más penoso: que desde su altas murallas la mujer del que fue mi profesor de filosofía en el último año del liceo, se había tirado al vacío, cumpliendo así con su deseo de suicidarse. Esta mujer no la conocí, por supuesto, pero en el primer día de clase, su viudo -nuestro profesor de filosofía- nos contó su historia. Creo acordarme de que, aun sin haber leído muchos de los textos que teníamos que estudiar, por vagancia, por desidia, por lisa y llana pereza, le tomé afecto a este profesor que, pese a la indudable tristeza que embargaba su vida, era un buen profesor, apasionado por su materia (lo mismo pasaba con las clases de historia del arte que también nos daba; estudiamos todo el siglo XX y mi perenne interés por las vanguardias -plásticas, musicales, literarias- viene de ahí). Y me acuerdo también de que, durante este último año de liceo, la muerte estaba decididamente al acecho, porque dos de los chicos de mi curso (un chico y una chica, no éramos amigos íntimos, pero me llevaba bien con ellos) murieron en un accidente de coche. El día siguiente, a las ocho de la mañana, primera hora de clase, el profesor de filosofía, con cara demacrada, nos habló de nuevo de la muerte, antes de pedirnos que nos fuéramos y de aprovechar el día. Pero 
¿aprovecharlo para qué? ¿Para pensar en la muerte? No sabría decir si ese día pensé en la muerte o si mis camaradas lo hicieron, solo me acuerdo del silencio en el aula antes de salir, del patio vacío, ya que los alumnos de los otros cursos seguían con sus clases, y también de la cara cerrada de un amigo una mañana, otra mañana, pero se trataba de otra muerte, de otro suicidio, el de un amigo suyo que estudiaba en otro lugar y que yo apenas había visto un par de veces. Eso sí, me acuerdo de que no supe cómo reaccionar o que no reaccioné, sin preguntarme si había que reaccionar o no, o preguntándomelo, lo que impedía cualquier posible reacción. Otro "amigo" (con la distancia no me parece que lo fuera tanto, de ahí las comillas), sí que sobreactuó su reacción, de una manera, me parece ahora, algo penosa (le gustaba bajar línea, en este tema como en otros). o sea que sí, que pensamos en la muerte o que nos preguntamos en qué pensar mientras pensamos en la muerte fingiendo pensar en otra cosa o fingiendo pensar en ella para que los otros crean que sí, que pensamos en ella mientras pensamos en nosotros pensando en ella sin saber qué pensar, porque el pensar en ella nos opaca el pensamiento. Se puede pensar en muchas cosas, pero tarde o temprano estas cosas desembocan en la idea de la muerte. En un vacío, un absurdo. Una distancia, de nuevo. Otra vez lo infranqueable. Pero la muerte no es el tema, ya que, siendo el único, es todos los temas. Muertes, después de este penoso episodio (pese a que, paradójicamente, este último año de liceo fue el más feliz, con la salvedad de que no creo haberme sentido nunca realmente feliz en el liceo), muertes, digo, después, hubo otras, no muchas, pero algunas; o, a lo mejor, solo una, por lo menos en mi familia (mentira, también hubo la de un primo que nunca conocí), la de mi abuelo materno, 12 años después (pero él no vivía ni vivió nunca en Angers, a orillas del Maine, vivía en el sur, cerca del mar). También podría hablar, parafraseando el título de un lúcido libro de Daniel Guebel, de "mis escritores muertos", o de mi cineasta muerto, alentando la idea de que el arte tiene cierta incidencia sobre nuestras vidas (poco importa que haya conocido o no en persona a estos escritores, a este cineasta). Pero, para conjurar un poco la muerte, la supuesta negatividad que el pensar en ella conlleva, quiero evocar una imagen (casi la única que me queda) de este chico de mi clase que murió en ese accidente estúpido de coche (todos los accidentes de coche lo son), una imagen que me quedó grabada, una imagen banal de felicidad pasajera: nos veo a los dos sentados en un parapeto en el patio del liceo, bajo un benigno sol de primavera, probablemente pocos días antes del accidente (¿fue este día que él me prestó esa rapadora de pelo que seguí usando durante años hasta que se estropeara definitivamente, pensando fatalmente en él cada vez que la usaba (pocas, la verdad)?); no me acuerdo de qué pudimos charlar, posiblemente de música (en esta época la música me importaba más que la literatura), posiblemente de otra cosa. Este chico, cuyo nombre ahora se me escapa por completo (se me escapó hace años, diría, casi desde el principio), me pareció en este momento y sigue pareciéndome para toda la eternidad, un chico feliz. Me gustaría imaginarnos a los dos con la misma felicidad pasajera, el mismo sol benigno y primaveral (la douceur angevine de la que hablaba muchos siglos atrás el poeta Du Bellay, para proseguir con la visita turística), la misma charla intrascendente sobre música o futbol o cualquier otra cosa (aunque nunca me interesó el futbol, así que esto último me parece dudoso), pero no sentados en un parapeto en el patio del liceo, sino en las orillas del río, en estos muelles no muy alejados del castillo y del centro de la ciudad; las orillas del Maine que, dicho sea de paso, es muy corto, apenas $11 \mathrm{~km}$ de vida le bastan para desembocar irremediablemente en el potente, salvaje y bello Loira (incluso, algunos, según parece según Wikipedia- le niegan el estatuto de río autónomo, arguyendo que no es otra cosa que la prolongación de otro río, el Mayenne). Ahora bien, me doy cuenta de que estoy 
pecando de falta de precisión o, más bien, de que el pasaje de un idioma al otro (del materno al aprendido en el que estoy escribiendo ahora) me crea una duda, una confusión: siguiendo la terminología del francés, el Loira es lo que se llama un fleuve y el Maine, una rivière, diferencia de términos que estrictamente hablando no existe en castellano. De hecho, Wikipedia, otra vez, lo deja bien clarito: "Fleuve", dice el redactor anónimo, "est un terme ambigu en français", o sea un término ambiguo, una de estas cosas que a primera vista al locutor nativo le parecen obvias, pero cuya obviedad de pronto se desmorona apenas uno se pone a indagar. Digamos, para hacerla corta, que la diferencia vendría a ser básicamente una cuestión de tamaño (algo siempre subjetivo, como se sabe), que el Paraná, por ejemplo, nunca podría llegar a ser una rivière, siendo desde el vamos el fleuve por antonomasia, una de estas demostraciones de potencia que nos ofrece la naturaleza, porque sí, porque puede darse el gusto. Pero el Maine, una mera rivière, decididamente, no se parece para nada al Paraná (o eso me dijeron, nunca lo vi), ni en términos de tamaño, relativos o no, ni en los de mitología o de geografía. $11 \mathrm{~km}$ son un poco cortos que digamos para desarrollar una mitología (el Maine no tiene ningún Juanele; o si lo tiene, será un poeta regionalista de cuarta). Pero no importa, el Maine podría tener la mitología que uno quisiera otorgarle; pequeña mitología privada y portátil, hecha de impresiones medio olvidadas o, porque no, de ficciones que uno podría inventarse. Como esta imagen del chico muerto y yo, sentados los dos en sus orillas (algo que en la realidad no creo que haya ocurrido nunca), felizmente bañados por la luz primaveral, una tarde, digamos que a eso de las cuatro, cuatro y media, después de las clases (o habiéndonos saltado una clase, o la tarde entera de clases). Nuestro liceo, cuyo nombre era -en homenaje al poeta del siglo XVI ya citado, exponente local del Dolce stil nuovo- Joachim Du Bellay, ¿quedaba lejos del río (la rivière)? No creo. Podría verificarlo ya mismo en Google Map, pero qué más da. Digamos que quedaba cerca del río, digamos incluso que quedaba cerca del castillo o de la catedral (lo que no es cierto), digamos que toda esta geografía de puntos de interés de la ciudad (turísticos y privados) podría amontonarse en un espacio reducido, conveniente, manejable como un recuerdo grato (uno de estos escasos recuerdos agradables ligados a mis años de colegio y liceo; tan escasos, parece, que tengo que inventarlos). La idea, entonces, sería armar con todo esto una especie de repuesta personal frente al anonimato algo deprimente de esta foto sin gracia sacada de Google; un solo recuerdo, pero un recuerdo bello, bello y simple (y también algo melancólico, por la proximidad de la muerte, merodeando). Un recuerdo donde se podrían leer muchas cosas: las posibilidades truncas (morir a los 18 años), las posibilidades entonces insospechadas (escribir, 20 años después, este texto), una amistad en ciernes que nunca pudo verificarse, una felicidad pasajera (la del momento) y otra, siempre por venir, como un umbral. Y ahí estamos, entonces, los dos, sentados en una postura cualquiera, en la despreocupación típica de la adolescencia (una despreocupación imaginaria que es la tonalidad que le quiero dar a este momento), los pelos desmarañados y suavemente mecidos por la brisa (otro signo de despreocupación risueña), mirando vagamente el agua del río (el espectáculo gratis de lo que cambia sin cambiar), sonriendo discretamente, sin insistencia (es decir, sonriendo con naturalidad, sin tomarlo en cuenta, como una consecuencia lógica del estar bien), intercambiando apenas uno que otro comentario implícito (porque la adolescencia es la edad de lo implícito, lo que está por venir), dejando pasar un tiempo necesariamente infinito (porque una foto es un corte en el tiempo y este tiempo recortado dura para siempre). Infinito, también, porque nos encontramos en un cruce entre lo que está por terminar (el liceo, el fin de un largo ciclo) y lo que aún no empezó, otra vida, adulta si se quiere (aunque la adultez, a veces, como 
una foto que recorta el tiempo, se toma eternidades para llegar). Un infinito que, como todo recuerdo, se puede mejorar y adornar a gusto. Un recuerdo, a fin de cuentas, tan simple, eficiente y cursi como una vieja foto familiar. O sea que la única forma que encuentro de responder a esta foto robada de internet es con otra foto, imaginaria esta vez, como si las dos podrían reflejarse en un paralelismo algo forzado. Reflejarse, para proseguir un poco más con la cursilería, en este espejo de agua más o menos verde llamado río -o fleuve o rivière -, el Maine, no muy lejos del cual nací hace casi treinta y nueve años, y sobre el cual estoy escribiendo ahora en un idioma que mis padres ausentes de este relato vagamente autobiográfico y escrupulosamente monolingües según la costumbre de su generación- no podrían leer ni entender aun queriéndolo, como si escribir en otro idioma fuera una coartada perfecta para hablar de sí mismo y de sus muertos en una lengua privada, una lengua fuera de campo, como la distancia insalvable infranqueable, sí- que nos separa de la muerte, de los otros, incluso de nuestra propia historia.

2 de abril de 2018 